\title{
PENGARUH PELAYANAN TERHADAP KEPUASAN PELANGGAN PADA AJIB BAKERY JAKARTA
}

\author{
Roy Irawan \\ Universitas Bina Sarana Informatika \\ Jl.Margonda Raya Depok \\ royirawan148009@gmail.com
}

\begin{abstract}
To win the competition, the company must be able to give satisfaction to the customer. The efforts that will be made by the company to satisfy the needs of consumers with various strategies and various ways in the hope that customers feel satisfied and then willing to come back. Outline in the writing of this final assignment using quantitative outline with the method of observation, questionnaire method and literature study. From the results of research Influence Services Against Customer Satisfaction At Ajib Bakery Jakarta can be seen that the correlation coefficient test of 0.612 which means the service has a strong and positive relationship to customer satisfaction. Test $\mathrm{t}$ can be obtained $\mathrm{t}$ count of 5.414 and t table 2.00076 with the provision of two-party test- $\mathrm{t}$ table $\geq \mathrm{t}$ then $\mathrm{Ho}$ is rejected and $\mathrm{Ha}$ accepted. The coefficient of determination test obtained result of $37,4 \%$ and $62,2 \%$ influenced by other factor which not exist in this research. Regression equation test is $\mathrm{Y}=7.539+0.810 \mathrm{X}$ which means if there is no service then the value of customer satisfaction is 7,539 and if it increases 1 then the customer satisfaction increases by 0810 .
\end{abstract}

Keywords: Service, Customer Satisfaction

\begin{abstract}
Abstraksi - Dalam memenangkan persaingan, perusahaan harus mampu memberikan kepuasan pada pelanggan. Upaya - upaya yang akan dilakukan oleh perusahaan untuk memuaskan kebutuhan konsumen dengan berbagai strategi dan berbagai cara dengan harapan agar pelanggan merasa puas dan selanjutnya mau untuk datang kembali. Outline dalam penulisan penelitian ini menggunakan outline kuantitatif dengan metode observasi, metode kuesioner dan studi pustaka. Dari hasil penelitian Pengaruh Pelayanan Terhadap Kepuasaan Pelanggan Pada Ajib Bakery Jakarta dapat diketahui bahwa uji koefisien korelasi sebesar 0,612 yang berarti pelayanan mempunyai hubungan kuat dan positif terhadap kepuasaan pelanggan. Uji t dapat diperoleh hasil t hitung sebesar 5.414 dan $t$ tabel 2.0076 dengan ketentuan uji dua pihak $-t$ tabel $\geq \mathrm{t}$ hitung maka Ho ditolak dan Ha diterima. Uji koefisien determinasi diperoleh hasil sebesar 37,4\% dan $62,2 \%$ yang dipengaruhi oleh faktor lain yang tidak ada dalam penelitian ini. Uji persamaan Regresi bernilai $\mathrm{Y}=7.539+0.810 \mathrm{X}$ yang berarti jika tidak ada pelayanan maka nilai kepuasaan pelanggan sebesar 7.539 dan jika meningkat 1 maka kepuasaan pelanggan meningkat sebesar 0.810 .
\end{abstract}


Kata Kunci : Pelayanan, Kepuasan Pelanggan

\section{PENDAHULUAN}

Meningkatnya intensitas persaingan dan jumlah pesaing menuntut perusahaan untuk selalu memperhatikan kebutuhan dan keinginan konsumen serta berusaha memenuhi harapan konsumen dengan cara memberikan pelayanan yang lebih memuaskan daripada yang dilakukan oleh pesaing.

Dalam jangka panjang, ikatan seperti ini memungkinkan perusahaan untuk memahami dengan seksama harapan pelanggan serta kebutuhan mereka. Dengan demikian, perusahaan dapat meningkatkan kepuasan pelanggan di mana perusahaan memaksimumkan pengalaman pelanggan yang menyenangkan dan meminimumkan pengalaman pelanggan yang kurang menyenangkan.

Setiap perusahaan dituntut untuk membuat pelanggan merasa puas dengan memberikan penawaran dan pelayanan yang lebih baik, mengingat perusahaan harus mampu untuk mempertahankan posisi pasarnya ditengah persaingan yang semakin ketat untuk memenangkan persaingan, perusahaan harus mampu memberikan kepuasan pada pelanggan.

\section{METODOLOGI PENELITIAN}

Untuk melengkapi pengumpulan data bagi penulisan penelitian ini, peneliti telah menyusun berdasarkan data-data yang penulis peroleh dengan menggunakan metode:

1. Observasi

Dalam metode ini, penulis melakukan pengamatan langsung pada Ajib Bakery untuk mendapatkan data-data yang dibutuhkan dalam penelitian.

2. Wawancara

Dalam metode ini digunakan dengan melakukan Tanya-jawab langsung kepada pihak-pihak yang berwenang sehubungan dengan judul yang peneliti ambil dalam penelitian ini pada Ajib Bakery

3. Dokumentasi

Dalam metode ini penulis melakukan penelitian dengan cara membaca, membahas secara teoritis melalui beberapa catatan literatur dan bahan mata kuliah yang ada hubungannya dengan materi penyusunan penelitian ini 
Ivancevich, dkk dalam Mukarom dan Laksana (2015:80) mendifinisikan "Pelayanan adalah produk - produk yang tidak kasat mata (tidak dapat diraba) yang melibatkan usaha - usaha manusia yang menggunakan peralatan".

Menurut Gronroos dalam Mukarom dan Laksana (2015:80) pelayanan adalah aktivitas atau serangkaian aktivitas yang bersifat tidak kasat mata (tidak dapat diraba) yang terjadi akibat yang interkasi antara konsumen dan karyawan atau hal - hal lain yang disediakan oleh perusahaan pemberi pelayanan yang dimaksudkan untuk memecahkan permasalahan konsumen / pelanggan.

Moenir dalam Abdul Majid (2009:34) menyatakan "pelayanan merupakan serangkaian kegiatan untuk memenuhi kebutuhan pelanggan atas jasa yang mereka dapatkan dari suatu perusahaan".

Menurut Cadotte, dkk dalam Tjiptono (2012:311) "Kepuasaan pelanggan adalah perasaan yang timbul setelah mengevaluasi pengalaman pemakaian produk".

Menurut Fornell dalam Tjiptono (2012:311) mengemukakan bahwa, "Kepuasaan pelanggan adalah evaluasi purnabeli keseluruhan yang membandingkan persepsi terhadap kinerja produk dengan ekspektasi pra-pembelian".

\section{HASIL DAN PEMBAHASAN}

Banyaknya tingkat pengangguran di DKI Jakarta (tahun 2004), maka muncul sebuah ide untuk menyediakan lapangan pekerjaan dengan membangun sebuah usaha roti. Pada waktu itu, roti merupakan suatu produk yang sedang terpopuler dan digemari oleh masyarakat. Maka dari itu, dibentuklah perusahaan roti dikenal sebagai Ajib Bakery pada tanggal 17 April 2004.

Ajib bakery yang dipimpin oleh Ibu Hermawati, S.E., Seiring berjalannya waktu usaha ini mulai berkembang berkat keuletan dan kerja kerasnya. Semakin bertambahnya omset dan kebutuhan akan variasi makanan, maka Ibu Hermawati mulai mengembangkan sayapnya dengan membuka sub bagian, yaitu catering.

Ajib bakery mempunyai usaha ciri khas tersendiri dalam mengelolah maupun menyajikan masakan, sehingga masih aktif hingga saat ini karena terus mendapatkan hati dan para pencinta makanan. Ciri khas tersebut dapat dilihat dari beragam jenis 
masakan dan terus inovatifnya berbagai resep baru yang membuat rasa dan bentuk yang terus diciptakan.

Sebagai bagian dari rencana pengembangan usaha, kami memperluas ruang lingkup aktivitas usaha yang lebih intensif dengan memperluas outlet - outlet kami di beberapa perusahaan besar.

\section{Populasi dan Sampel}

Ajib Bakery kurang lebih mencapai 100 (seratus) responden per-minggu, populasi dari penelitian ini dimana terdapat populasi sebanyak 60 responden. Dari populasi tersebut diambil sampel dengan metode random yaitu sebanyak 51 responden (dilihat dari tabel sugiyono 2015).

Berdasarkan kuesioner yang penulis sebar kepada responden mengenai pelayanan dan kepuasaan pelanggan pada ajib bakery maka didapat karateristik responden berdasarkan jenis kelamin, usia, tingkat pendidikan terakhir dan pekerjaan responden.

a. Karateristik responden berdasarkan jenis kelamin

Tabel III. 1

Jenis Kelamin Responden

\begin{tabular}{|l|l|c|c|}
\hline No & Ienis Kelamin & Jumlah (Orang) & Persentase \% \\
\hline 1 & Laki - laki & 24 & $47 \%$ \\
\hline 2 & Perempuan & 27 & $53 \%$ \\
\hline \multicolumn{2}{|c|}{ Total } & 51 & $100 \%$ \\
\hline
\end{tabular}

Sumber: Data diolah dari kuesioner

Berdasarkan tabel terlihat yang dijadikan objek penelitian lebih banyak perempuan dibandingkan dengan laki - laki. Laki - laki sebanyak 24 dengan persentase sebanyak $47 \%$ dan perempuan sebanyak 27 dengan persentase $53 \%$.

b. Karateristik responden berdasarkan usia

Tabel III. 2

Usia Responden

\begin{tabular}{|l|l|c|c|}
\hline No & Usia & Jumlah (0rang) & Persentase $\%$ \\
\hline 1 & $20-25$ & 32 & $62 \%$ \\
\hline 2 & $26-40$ & 11 & $22 \%$ \\
\hline 3 & $>40$ & 8 & $16 \%$ \\
\hline \multicolumn{2}{|c|}{ Total } & $\mathbf{5 1}$ & $\mathbf{1 0 0} \%$ \\
\hline
\end{tabular}

Sumber: Data diolah dari kuesioner 
Berdasarkan tabel diatas terlihat responden yang berusia 20 - 25 tahun lebih banyak 32 orang dengan presentase $62 \%$, usia $26-40$ tahun sebanyak 11 orang dengan persentase $22 \%$, dan usia $>40$ tahun sebanyak 8 orang dengan persentase $16 \%$

\section{Uji Instrumen Penelitian}

a. Uji Validitas

1) Hasil Analisis Butir Pernyataan Pelayanan

Tabel III. 3

\section{Uji Validitas}

\begin{tabular}{|r|c|c|c|}
\hline \multicolumn{1}{|c|}{ No } & R Hitung & R Tabel & Keterangan \\
\hline 1 & 0.520 & 0.276 & Valid \\
\hline 2 & 0.630 & 0.276 & Valid \\
\hline 3 & 0.677 & 0.276 & Valid \\
\hline 4 & 0.621 & 0.276 & Valid \\
\hline 5 & 0.715 & 0.276 & Valid \\
\hline 6 & 0.560 & 0.276 & Valid \\
\hline 7 & 0.540 & 0.276 & Valid \\
\hline 8 & 0.551 & 0.276 & Valid \\
\hline 9 & 0.407 & 0.276 & Valid \\
\hline 10 & 0.424 & 0.276 & Valid \\
\hline
\end{tabular}

Sumber:data diolah dari kuesioner

2) Hasil Analisis Butir Pernyataan Kepuasan Pelanggan

Tabel III. 4

Uji Validitas

\begin{tabular}{|c|c|c|c|}
\hline No & R Hitung & R Tabel & Keterangan \\
\hline 1 & 0.517 & 0.276 & Valid \\
\hline 2 & 0.639 & 0.276 & Valid \\
\hline 3 & 0.647 & 0.276 & Valid \\
\hline 4 & 0.754 & 0.276 & Valid \\
\hline 5 & 0.788 & 0.276 & Valid \\
\hline 6 & 0.806 & 0.276 & Valid \\
\hline 7 & 0.666 & 0.276 & Valid \\
\hline 8 & 0.677 & 0.276 & Valid \\
\hline 9 & 0.726 & 0.276 & Valid \\
\hline 10 & 0.742 & 0.276 & Valid \\
\hline
\end{tabular}

Sumber:data diolah dari kuesioner

Berdasarkan data yang terkumpul dari 51 responden yang ditunjukan dalam tabel III. 4 dan tabel III. 5, maka terdapat 20 koefesien korelasi (jumlah butir 20). Hasil perhitungan uji validitas SPSS 22 dibandingkan dengan pada derajat dimana adalah jumlah responden 51 sehingga nilai yang digunakan adalah $r$ tabel dengan derajat 51 dengan taraf signifikan 0.05, sehingga $r$ tabel sebesar 0,276. Ternyata $r$ Hitung $>r$ Tabel maka semua pernyataan dinyatakan valid.

b. Uji Reliabilitas Instrument 
Dalam melakukan pengujian reliabilitas instrument, penulis melakukan uji reliabilitas Alpha Cronbach's SPSS 22. Berikut hasil perhitungannya :

1). Hasil Analisis Butir Penyataan Pelayanan

Tabel III. 5

Reliabilitas Pelayanan

Reliability Statistics

\begin{tabular}{|r|r|}
\hline $\begin{array}{c}\text { Cronbach's } \\
\text { Alpha }\end{array}$ & N of Items \\
\hline .766 & 10 \\
\hline
\end{tabular}

Sumber : Data Primer Hasil Kuesioner yang diolah menggunakan SPSS 22

Berdasarkan hasil perhitungan diatas, dapat diketahui bahwa nilai Cronbach's alpha sebesar 0,766. Hasil tersebut dibandingkan dengan nilai $r$ pada $r$ tabel jumlah responden 51, sehinggan nilai yang digunakan tabel $\mathrm{r}$ dengan nilai derajat bebas 51 dengan taraf signifikan 0.05 sehingga diperoleh nilai $r$ tabel sebesar 0,60 . Ternyata nilai alpha >dari $r$ tabel, yang artinya semua pernyataan tersebut reliabel.

\section{Hasil Analisis Butir Pernyataan kepuasan}

Tabel III. 6

\section{Reliabilitas Kepuasan}

Reliability Statistics

\begin{tabular}{|r|r|}
\hline $\begin{array}{c}\text { Cronbach's. } \\
\text { Alpha }\end{array}$ & N of Items \\
\hline .884 & 10 \\
\hline
\end{tabular}

Sumber : Data Primer Hasil Kuesioner yang diolah menggunakan SPSS 22

Berdasarkan hasil perhitungan diatas, dapat diketahui bahwa nilai Cronbach's alpha sebesar 0,884. Hasil tersebut dibandingkan dengan nilai $\mathrm{r}$ pada $\mathrm{r}$ tabel jumlah responden 51, sehinggan nilai yang digunakan tabel $\mathrm{r}$ dengan nilai derajat bebas 51 dengan taraf signifikan 0.05 sehingga diperoleh nilai $r$ tabel sebesar 0,60 . Ternyata nilai alpha >dari $\mathrm{r}$ tabel, yang artinya semua pernyataan tersebut reliabel.

\section{Data Hasil Kuesioner Variabel Pelayanan}

Berdasarkan kuesioner yang penulis sebar ke 51 responden terkumpul hasil, kuesinoer tersebut untuk dijadikan tolak ukur dalam perhitungan korelasi product 
moment pearson. Untuk mengetahui hasil rekapitulasi jawaban responden, maka dapat dijelaskan pada tabel III.7 Sebagai berikut:

Tabel III. 7

\section{Data Hasil Kuesioner Pelayanan}

\begin{tabular}{|c|c|c|c|c|c|c|}
\hline \multirow{2}{*}{ Pernyataan } & \multicolumn{5}{|c|}{ Skor Jawaban \% } & \multirow{2}{*}{$\begin{array}{c}\text { Jumlah } \\
\text { Skor }\end{array}$} \\
\cline { 2 - 6 } & 1 & 2 & 3 & 4 & 5 & \\
\hline $\mathrm{X} 1$ & & 1.96 & 3.92 & 31.37 & 62.75 & 232 \\
\hline $\mathrm{X} 2$ & & & 5.88 & 33.33 & 60.78 & 232 \\
\hline $\mathrm{X} 3$ & & & 7.84 & 37.25 & 54.90 & 228 \\
\hline $\mathrm{X} 4$ & & & 1.96 & 50.98 & 47.06 & 227 \\
\hline $\mathrm{X} 5$ & & 5.88 & 3.92 & 37.25 & 52.94 & 223 \\
\hline $\mathrm{X} 6$ & & & 7.84 & 49.02 & 43.14 & 222 \\
\hline $\mathrm{X} 7$ & & & 1.96 & 47.06 & 50.98 & 229 \\
\hline $\mathrm{X} 8$ & & & 1.96 & 41.18 & 56.86 & 232 \\
\hline $\mathrm{X} 9$ & & & 1.96 & 52.94 & 45.10 & 226 \\
\hline $\mathrm{X} 10$ & & & 0.00 & 49.02 & 50.98 & 230 \\
\hline Total & $\mathbf{7 . 8 4}$ & $\mathbf{3 . 7 3}$ & $\mathbf{4 2 . 9 4}$ & $\mathbf{5 2 . 5 5}$ & \\
\hline
\end{tabular}

Sumber : Data Diolah Ajib Bakery

Berdasarkan Tabel III. 7 diatas dapat diketahui bahwa rata-rata responden puas dengan pelayaann yang diberikan dilihat dari hasil kuesioner responden yang menjawab sangat setuju dan setuju dengan persentase $52.55 \%$ dan $42.94 \%$, namun masih ada yang menjawab ragu-ragu dan tidak setuju dengan persentase sebanyak $3.73 \%$ dan 0.78 $\%$

\section{Data Hasil Kuesioner Variabel Kepuasan Pelanggan}

Setelah terkumpul hasil kuesioner yang penulis sebar ke 51 responden, penulis mengambil semua kuesioner untuk dijadikan tolak ukur dalam perhitungan korelasi pearson. Untuk mengetahui hasil rekapitulasi jawaban responden, maka dapat dijelaskan pada tabel III. 8 Sebagai berikut:

Tabel III. 8

Rekapitulasi Jawaban Responden Terhadap Kepuasan Pelanggan

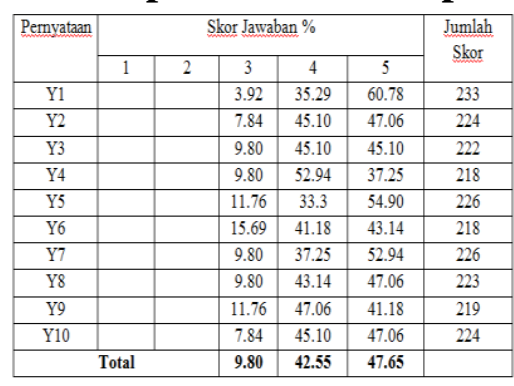

Sumber : Data Diolah Ajib Bakery

Berdasarkan tabel III.8 diatas dapat diketahui bahwa rata-rata responden sangat puas dengan pelayanan yang diberikan Ajib Bakery dilihat dari hasil kuesioner 
responden yang menjawab sangat setuju dan setuju persentasenya sebesar 47.65 dan $42.55 \%$. Namun masih ada yang menjawab Ragu-ragu sebesar $9.80 \%$.

\section{Analisis Pelayanan Terhadap Kepuasan Pelanggan}

\section{a. Uji Koefesien Korelasi}

Untuk menguji koefesien korelasi maka digunakan perhitungan korelasi dengan menggunakan SPSS 22. Korelasi yang penulis gunakan adalah korelasi sederhana, hasilnya sebagai berikut:

Tabel III. 9

Uji Koefesien Korelasi

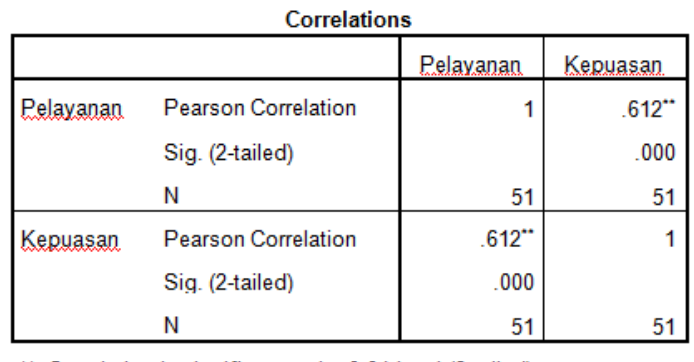

**. Correlation is significant at the 0.01 level (2-tailed).

Sumber : Data Primer Hasil Kuesioner yang diolah menggunakan SPSS 22

Korelasi antara pelayanan dengan kepuasan memberikan nilai koefesien sebesar 0.612. Karena koefesien mendekati dan nilai koefesien terletak pada interval seperti pada tabel maka dapat disimpulkan bahwa hubungan antara pelayanan dan kepuasan pelanggan kuat. Angka koefesien positif menunjukan hubungan positif, yaitu jika pelayanan meningkat, maka kepuasan pelanggan juga akan meningkat.

Menurut Priyatno (2014:113) Langkah-langkah untuk menentukan hubungan anatara dua variabel sebagai berikut :

1. Menentukan Hipotesis :

Ho : tidak ada hubungan antara pelayanan dengan kepuasan pelanggan.

$\mathrm{Ha}$ : adanya hubungan antara pelayanan dengan kepuasan pelanggan.

2. Kriteria pengujian :

Jika signifikan > 0.1 maka Ha diterima

Jika signifikan $<0.1$ Ho ditolak

3. Membuat kesimpulan 
Dari tabel III.11Didapat signifikan $<0.1$ maka Ho ditolak. Jadi, dapat disimpulkan bahwa ada hubungan antara pelayanan dengan kepuasan pelanggan.

\section{b. Uji Koefesien Determinasi}

Untuk mengetahui seberapa besar pengaruh variabel X (Pelayanan) terhadap variabel Y (Kepuasan pelanggan), maka digunakan uji koefesien determinasi yang perhitungannya menggunakan SPSS 22. Berikut hasil perhitungannya.

Tabel III.10

Uji Koefesien Determinasi

\begin{tabular}{|l|r|r|r|c|}
\hline & \multicolumn{1}{|c|}{ Model Summary } \\
\hline Model & R & R Square & \multicolumn{1}{c|}{$\begin{array}{c}\text { Adjusted R } \\
\text { Square }\end{array}$} & $\begin{array}{c}\text { Std. Error of the } \\
\text { Estimate }\end{array}$ \\
\hline 1 & $.612^{\mathrm{a}}$ & .374 & .361 & 3.673 \\
\hline
\end{tabular}

a. Predictors: (Constant), Pelayanan

Sumber : Data Primer Hasil Kuesioner yang diolah menggunakan SPSS 22

Dari tabel diatas dapat dilihat bahwa $\mathrm{R}$ Square $\left(\mathrm{R}^{2}\right)$ menunjukan koefesien determinasi. Angka tersebut akan diubah ke dalam bentuk persen. Nilai $\mathrm{R}^{2}$ sebesar 0,612. Artinya persentase sumbangan pengaruh variabel pelayanan terhadap kepuasan pelanggan sebesar $37,4 \%$, sedangkan sisanya $62,6 \%$ dipengaruhi oleh faktor lain yang tidak dimasukan ke dalam model ini.

\section{c. Uji Persamaan Regresi}

Untuk mengetahui seberapa besar peningkatan dan penurunan kepuasan pelanggan, maka digunakan uji persamaan regresi yang dihitung dengan SPSS 22. Penulis menggunakan regresi sederhana, hasil perhitungan sebagai berikut :

Tabel III. 11

Uji Persamaan Regresi

\begin{tabular}{|c|c|c|c|c|c|c|}
\hline \multirow[b]{2}{*}{ Model } & & \multicolumn{2}{|c|}{ Unstandardized Coefficients } & $\begin{array}{l}\text { Standardized } \\
\text { Coefficients }\end{array}$ & \multirow[b]{2}{*}{ T } & \multirow[b]{2}{*}{ Sig. } \\
\hline & & B & Std. Error & Beta & & \\
\hline 1 & (Constant) & 7.539 & 6.715 & & 1.123 & .267 \\
\hline & Pelayanan & .810 & .150 & .612 & 5.414 & .000 \\
\hline
\end{tabular}

a. Dependent Variable: Kepuasan

Sumber : Data Primer Hasil Kuesioner yang diolah menggunakan SPSS 22 
Nilai-nilai pada tabel III.11 Kemudian dimasukan kedalam persamaan regresi sebagai berikut :

$$
\begin{aligned}
Y & =a+b X \\
& =7.539+0.810 X
\end{aligned}
$$

Menurut Priyatno (2014:136) menjelaskan bahwa arti angka pada persamaan diatas adalah sebagai berikut :

1. Nilai konstans (a) adalah 7.539 artinya, jika pelayanan bernilai 0 (nol), maka kepuasan pelanggan bernilai 7.539.

2. Nilai koefesien regresi variabel (b) bernilai positif, yaitu 0.810 , ini dapat diartikan bahwa setiap peningkatan Pelayanan sebesar 1, maka kepuasan pelanggan meningkat 0.810 .

Menurut Priyatno (2014:136) langkah-langkah untuk menentukan pengaruh antara dua variabel sebagai berikut :

1. Menentukan Hipotesis :

Ho : Pelayanan tidak berpengaruh terhadap kepuasan pelanggan

Ha : Pelayanan berpengaruh terhadap kepuasan pelanggan

2. Menentukan T Hitung dan Signifikan

Dari tabel diatas dapat dihitung sebesar 5.414 dan signifikan 0,000

3. Menentukan T tabel

T tabel dapat dilihat pada tabel III.11 Pada signifikan $0,05 / 2=0,25$ dengan derajat kebebasan $\mathrm{df}=\mathrm{n}-2$ jadi $51-2=49$. Hasil yang diperoleh untuk t tabel sebesar 2.0076 (lihat pada lampiran t tabel).

4. Kriteria Pengujian :

Jika $-\mathrm{t}$ tabel $\leq \mathrm{t}$ hitung $\leq$ tabel, maka Ha diterima.

Jika $-\mathrm{t}$ hitung $<-$ tabel atau $\mathrm{t}$ hitung $>\mathrm{t}$ tabel, maka Ho ditolak.

Berdasarkan signifikasi :

- Jika signifikasi > 0,1 maka Ha diterima

- Jika signifikasi < 0,1 maka Ho ditolak.

5. Membuat kesimpulan 
Karena nilai t hitung $>$ tabel $(5.414>2.0076)$ dan Signifikan $<0,05(0,000<0,05)$ Maka Ho ditolak. Jadi dapat disimpulkan bahwa pelayanan berpengaruh terhadap kepuasan.

\section{KESIMPULAN}

Berdasarkan hasil penelitian maka penulis dapat mengambil kesimpulan tentang Pengaruh Pelayanan Terhadap Kepuasaan Pelanggan Pada Ajib Bakery Jakarta Sebagai berikut :

1. Ajib Bakery Jakarta adalah perusahaan yang bergerak dibidang makanan dan jasa pelayanan makanan dan minuman. Ajib bakery menyediakan berbagai jenis roti dan snack yang menu utamanya roti buaya.

2. Ajib bakery sangat memperhatikan beberapa faktor dalam meningkatkan pelayanan untuk memenuhi kepuasaan para pelanggannya. Hal tersebut dapat dilihat dari hasil yang penulis teliti ini yang mengatakan "setuju" dengan rata - rata 50\% responden dalam kuesioner pelayanan terhadap kepuasaan pelanggan

3. Dari hasil penelitian yang telah penulis teliti, koefisien korelasi yang ditemukan $r$ sebesar 0.612 termasuk pada kategori "kuat". Jadi terdapat hubungan yang kuat antara pelayanan dan kepuasaan pelanggan.

4. Berdasarkan perhitungan determinasi yang penulis teliti, diperoleh hasilnya yaitu varian yang terjadi pada variabel kepuasaan pelanggan $37.4 \%$ ditentukan oleh varian yang terjadi pada variabel pelayanan. Pengertian ini sering diartikan pengaruh pelayanan terhadap kepuasaan pelanggan $37.4 \%$ dan sisanya $62,6 \%$ ditentukan faktor lain seperti fasilitas, promosi dan lain - lain yang masih membutuhkan penelitian lebih lanjut.

Hasil persamaan regresi yang penulis teliti, koefisien regresi $y=a+b X$ sebesar $7.359+0.810 \mathrm{X}$ menyatakan bahwa setiap penambahan, pelayanan perusahaan akan meningkatkan kepuasaan pelanggan sebesar 0.810 .

\section{DAFTAR PUSTAKA}

Duwi. Priyatno. 2014. SPSS 22 Pengelolaan Data Terpraktis. Yogyakarta : CV Andi Offset 
Majid, Suharto Abdul. 2009. Customer Service Dalam Bisnis Jasa Transportasi. Jakarta:PT Rajagrafindo Persada.

Mukarom dan Laksana. 2015. Manajemen Pelayanan Publik. Bandung : CV Pustaka Setia

Sugiyono. 2013. Statistika Untuk Penelitian. Bandung:Alfabeta. , 2014. Metode Penelitian Kuantitatif Kualitatif dan R\&D. Penerbit.Alfabeta: Bandung

Tjiptono, Fandy. 2012. Sevice Management Mewujudkan Layanan Prima. Yogyakarta:CV Andy Offset 